\title{
sciendo
}

CIVIL AND ENVIRONMENTAL ENGINEERING REPORTS

E-ISSN 2450-8594

CEER 2019; 29 (2): 101-116

DOI: $10.2478 /$ ceer-2019-0019

Original Research Article

\section{INVESTIGATION OF LOAD CAPACITY OF STEEL CONCRETE COMPOSITE COLUMNS SRC REINFORCED BY IPE}

\author{
Peyman BEIRANVAND ${ }^{1}$, Matin ABDOLLAHIFAR ${ }^{2}$ \\ Ahmad MORADPOUR $^{3}$, Saeideh SADEGHI GOLMAKANI ${ }^{4}$ \\ ${ }^{1}$ Lecturer, Department of Civil Engineering, Lorestan University, Khorramabad, Iran \\ ${ }^{2}$ M.Sc, Department of Civil Engineering, Zanjan University, Zanjan, Iran \\ ${ }^{3} \mathrm{PhD}$ Candidate, Khorramabad Branch, Islamic Azad University, Iran \\ ${ }^{4}$ M.Sc, Department of Civil Engineering, Ferdowsi University, Mashhad, Iran
}

\begin{abstract}
In this study, a column with section IPE and different lengths, completely embedded in concrete, is modelled by finite element software ABAQUS. Columns under different biaxial loading were used and graphs of axial force-axial deformation, interaction axial force, and bending moment and column curve were mapped. The results show that the load capacity of the column, with increasing length and also increasing eccentricity of the axial load, will be reduced. With increasing length, the effect of an increased eccentricity of the reduced load capacity was increased. Equations for the design of the column are also presented. The results of the presented equations were compared with the values obtained from finite element and building national institute $10^{\text {th }}$ topic.
\end{abstract}

Keywords: Steel-Concrete composite columns SRC, Finite element, Bi-Axially loaded.

\footnotetext{
${ }^{1}$ Corresponding author: lecturer, Department of Civil Engineering, Lorestan University, Khorramabad, Iran; e-mail: peyman51471366@gmail.com
} 


\section{INTRODUCTION}

Concrete and steel are materials that are mainly used in buildings. The advantages of both materials are completely understood nowadays. Concrete is a material with high hardness, inexpensive compared to other materials and having remarkable stability against fire - steel is also a material with high formation and resistance and low weight. Yet using only steel in building columns, especially tall buildings, is not economic. Also, tall buildings with steel columns usually have relatively significant deformations and low resistance to fire.

Using ferro-concrete in tall buildings columns in lower floors allows occupying a larger space and has relatively more weight. Also, due to concrete eagerness, the result will have lower deformation and vibrating loads will lead to resistance loss. A smart composite of these two materials will lead to a more efficient system than using them separately. Steel-concrete composite columns have gradually prevailed since 1950 [2] and, due to their great advantages, using them in tall buildings has increased rapidly. Economic comparison between composite columns and steel columns revealed that, in composite columns, about 40 to 50 percent less steel is used than with steel columns and, also in composite columns, about 65 to 80 percent less concrete and 10 percent more steel is used [7]. However, concrete-steel composite columns have been used extensively in building and other constructions and their usage is increasing, nevertheless, these columns are taken as steel and ferro-concrete and the continuous collaboration between steel and concrete is neglected. Efficient and effective use of steel-concrete composite columns, therefore, needs a different look to steel and concrete columns in order to enter into the design process of these columns. Few design regulations with any degree of reliability have been stated in statute for designing steel-concrete composite columns so that we can only refer to AISC-2010, EC-4-2004, BS-5400200h regulations [2]. The reader is referred to reference number [4] to see calculation examples of designing steel- concrete composite columns.

\section{INTRODUCING STEEL-CONCRETE COMPOSITE COLUMNS}

Steel-concrete composite columns are classified into two overall categories; concrete filled Tube (CFT) columns and steel Reinforced concrete (SRC) columns. Combining these two categories, CFT columns and SRC with steel section (SRC-CFT) and also SRC columns with a section filled with concrete 
(CFT-SRC) are examples of steel - concrete composite columns. Steel concrete composite columns are shown in figures from 1 to 4 .
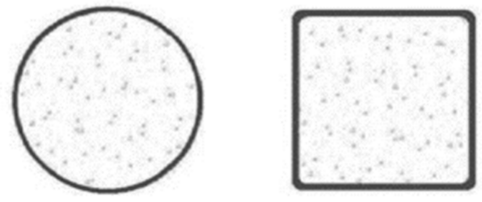

Fig. 1. Two common types of CFT columns
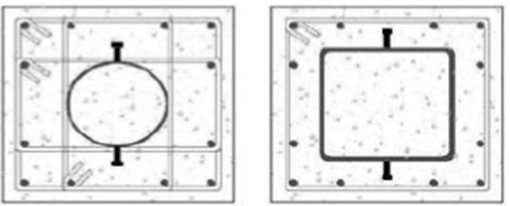

Fig. 3. Two samples of SRC-CFT columns
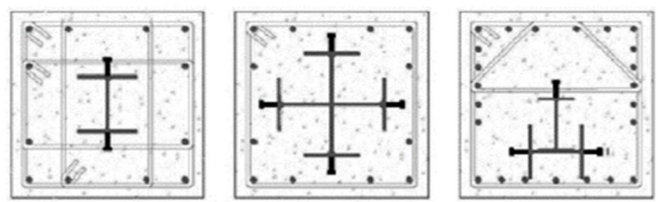

Fig. 2. Three samples of SRC columns
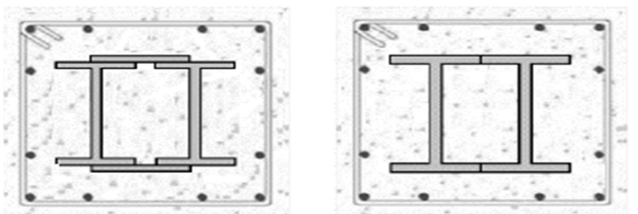

Fig. 4. Two samples of CFT-SRC columns

The main fault in CFT columns is low resistance to fire because the steel is uncovered in these columns. This flaw is partially resolved in SRC columns as there is a supportive concrete cover to shield against drastic temperature increase in the presence of fire; however, implementing composites in SRC columns is correspondingly harder than for CFT columns as they have more details. Combining the CFT columns with SRC columns can lead to usage of the best of both columns. CFT - SRC columns have more resistance against fire and corrosion compared to SRC-CFT since, like the SRC columns, a concrete cover acts as a shield against drastic temperature increase in the presence of fire.

\section{STEEL AND CONCRETE MODELLING METHOD IN ABAQUS SOFTWARE}

In ABAQUS software, three models are used: plastic damage behaviour model, cracking model for concrete, and concrete smeared cracking model. In this study, the plastic damage behaviour model is used for concrete modelling. This model is based on the hardening and softening behaviour of pseudo brittle materials like concrete [11]. The real weakness in the mechanism of brittle materials like concrete is cracking under tension and smashing under pressure. To create the strain- stress curve of concrete under pressure, destiny equations have been used. In these equations, a hyperbola equation has been used for 
practising the concrete strain - steel curve. In this curve, the strain - steel equation is formulated based on 28 days pressure resistance of source cylinder sample concrete $\mathrm{f}_{\mathrm{c}}$, maximum tension of corresponding strain $\varepsilon_{0}$, and for concrete elasticity modulus, as written by equations (3.1) to (3.4) [12].

$\mathrm{f}_{\mathrm{c}}=\mathrm{f}_{\mathrm{c}}^{\prime \prime}\left(\frac{2 \varepsilon_{\mathrm{e}}}{\varepsilon_{0}}-\left(\frac{\varepsilon_{\mathrm{c}}}{\varepsilon_{0}}\right)^{2}\right)$

$\varepsilon_{0}=1.8 \frac{\mathrm{f}_{\mathrm{c}}}{\mathrm{E}_{\mathrm{c}}}$

$\mathrm{E}_{\mathrm{c}}=4700 \sqrt{\mathrm{f}_{\mathrm{c}}}$

$\mathrm{f}_{\mathrm{c}}^{\prime \prime}=\mathrm{k}_{\mathrm{s}} \mathrm{f}_{\mathrm{c}}^{\prime}$

Where $\mathrm{f}_{\mathrm{c}}^{\prime \prime}$ is the maximum pressure tension that could be made in concrete. $\mathrm{k}_{\mathrm{s}}$ concrete equals $15,20,25,30$ and or larger than $35 \mathrm{MPa}$ is considered for 1 , $0.97,0.95,0.93,0.92$ respectively. In this research, concrete with a pressure resistance of $\mathrm{f}_{\mathrm{c}}^{\prime}=25 \mathrm{MPa}$ has been used. $\mathrm{E}_{\mathrm{c}}$ is the concrete elasticity modulus and $\mathrm{f}_{\mathrm{c}}$ is the tension in a strain of $\varepsilon_{\mathrm{c}}$. Researchers have considered various models for concrete strain - steel behaviour, some of which are shown in figure 5. In this figure, $\mathrm{f}_{\mathrm{cr}}$ is the stress tension corresponding to the concrete cracking under direct tension. In this research, our owen curve is used [8]. This curve has been shown in figure 5 [9]. $\varepsilon_{\mathrm{t}}^{\prime}$ is in net strain of about 0.0001 and in tension due to bending in the range of 0.00014 to 0.0002 . In this article, $\varepsilon_{\mathrm{t}}^{\prime}$ is 0.00014 and according to $\mathrm{E}=2500 \mathrm{MPa}, \mathrm{F}_{\mathrm{cr}}=35 \mathrm{MPa}$ is gained.

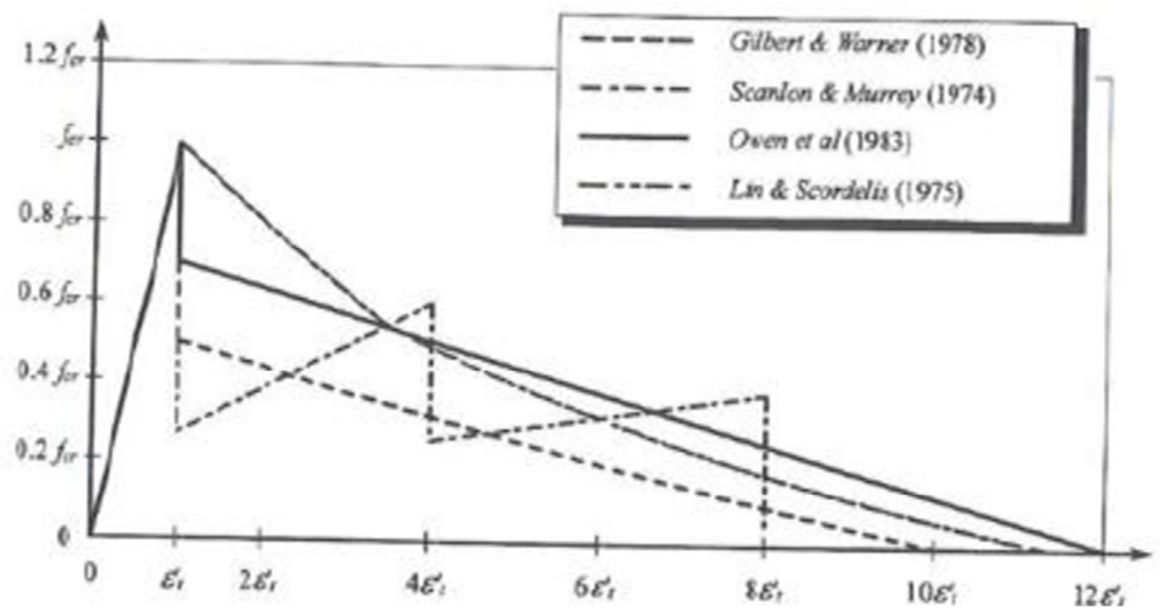

Fig. 5. Some proposed models for concrete street-stain behaviour under tension [9] 
Concrete poisson coefficient for high - resistance concrete is about 0.11 and 0.21 for low- resistance concrete. [9]In this study, 0.2 has been used. Introducing steel in the ABAQUS software enabled determining elasticity model parameters, poisson coefficient, and plastic stress- strain curve. Elasticity modulus, yielding tension, final resistance, and poisson coefficient for section IPE are $2.1 \times 10^{5} \mathrm{MPa}, 240 \mathrm{MPa}, 370 \mathrm{MPa}$ and 0.2 , respectively. Also, Armature class S340 with yielding tension of $340 \mathrm{Mpa}$ and final resistance of $500 \mathrm{MPa}$ has been used. The steel plastic strain-stress curve must be introduced as a table function to the software. In the case of having no access to these data, we can use the models presented by researchers. The model thus used for longitudinal armature and steel section in columns SRC is shown in figures 6 and $7[5,1]$.

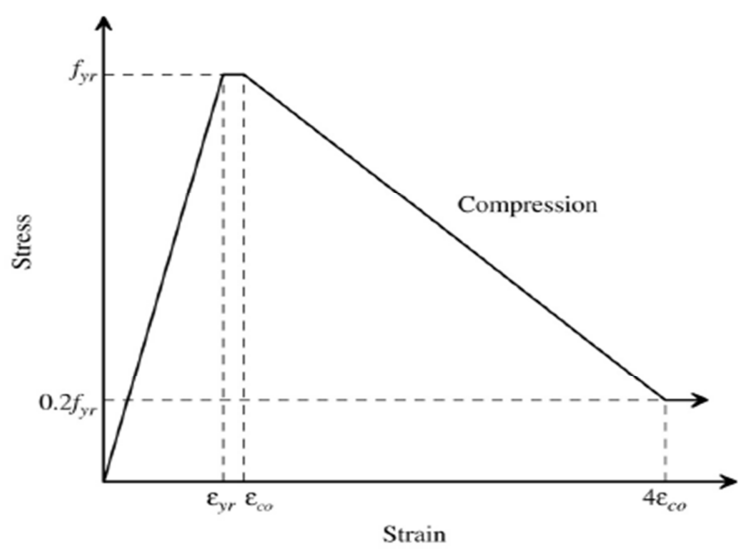

Fig. 6. Stress-strain relation for a longitudinal reinforcing bar in compression [1]

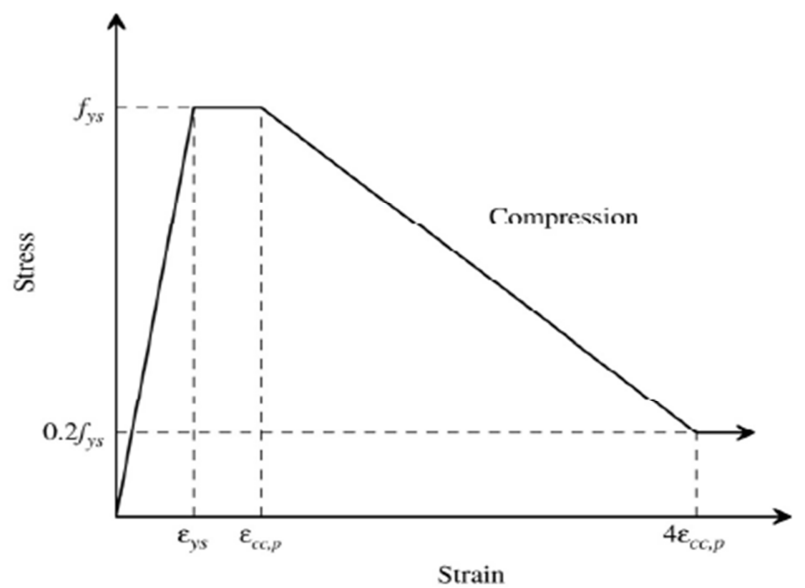

Fig. 7. Stress-strain relation for a structural steel section in compression [1] 
Generally, for modelling the longitudinal armatures in reinforced concrete and or composite parts under bending moment, the same behaviour has been considered in tension and pressure [6]. However, significant longitudinal armatures' buckling occurs in non- elastic deformation where parts are under axial pressure force. When the concrete cover reaches a corresponding strain with its maximum tension $\left(\varepsilon_{\mathrm{co}}\right)$, the rebars experience buckling and lose resistance. After buckling, longitudinal armature yielding tension reduced to $20 \%$ of its yielding resistance and then remained constant. At this time, the longitudinal armature strain reaches $4 \varepsilon_{\text {co }}$. Similar behaviour with longitudinal armature is seen with the steel section.

After concrete cracking around the steel section which is partially embedded, with strain equal to $\varepsilon_{\mathrm{cc}, \mathrm{p}}$, the steel section flange experiences local buckling. As the strain in the steel section reaches $4 \varepsilon_{\mathrm{cc}, \mathrm{p}}$, stress increases to $20 \%$ of steel yielding tension. For simulating steel in concrete in ABAQUS software, four methods are used being Rebar method, Rebar layer method, embedded element method, and partition method. In this research, we have used the embedded element method. It is clear that the Rebar free tip degrees and steel section embedded in concrete dependent from surrounding concrete.

To include such a problem, a capability called "Embedded" has been put in the ABAQUS software. Using this capability, we can put a segment in another segment in such a way that the inner segment has free of degrees. Rebars and steel sections are thereby regarded as completely involved with the concrete in the software and interaction between steel and concrete is calculated by the software. C3CR8 element concrete and steel section, and T3D2 element for longitudinal rebars have been used. Concrete element dimensions depend on type and place of use but in general must be up to four times larger than concrete granules. There are two reasons for this issue:

A) If the element size is smaller than the average stone size, the defined features are no longer associated with the concrete but belong to cement and stones.

B) If the calculated crack length from a finite element is going to be correct, concrete element dimensions must be smaller than quadruple concrete granules. It is noteworthy that the crack width in the element is equal to multiplying the strain by the element length along the crack. In this study, $40 \mathrm{~mm}$ dimensions were used for the concrete and steel. 


\section{EXPLORED COLUMNS CHARACTERISTICS}

In this study, steel columns with section IPE180, completely embedded in concrete, with modelled columns having section area of $350 \mathrm{~mm} \times 400 \mathrm{~mm}$ were used. In the model, $14 \mathrm{~mm}$ concrete was used as longitudinal armature with strips of $10 \mathrm{~mm}$ diameter and $200 \mathrm{~mm}$ distance [3]. A view of the model without showing concrete is given in figure 8 .

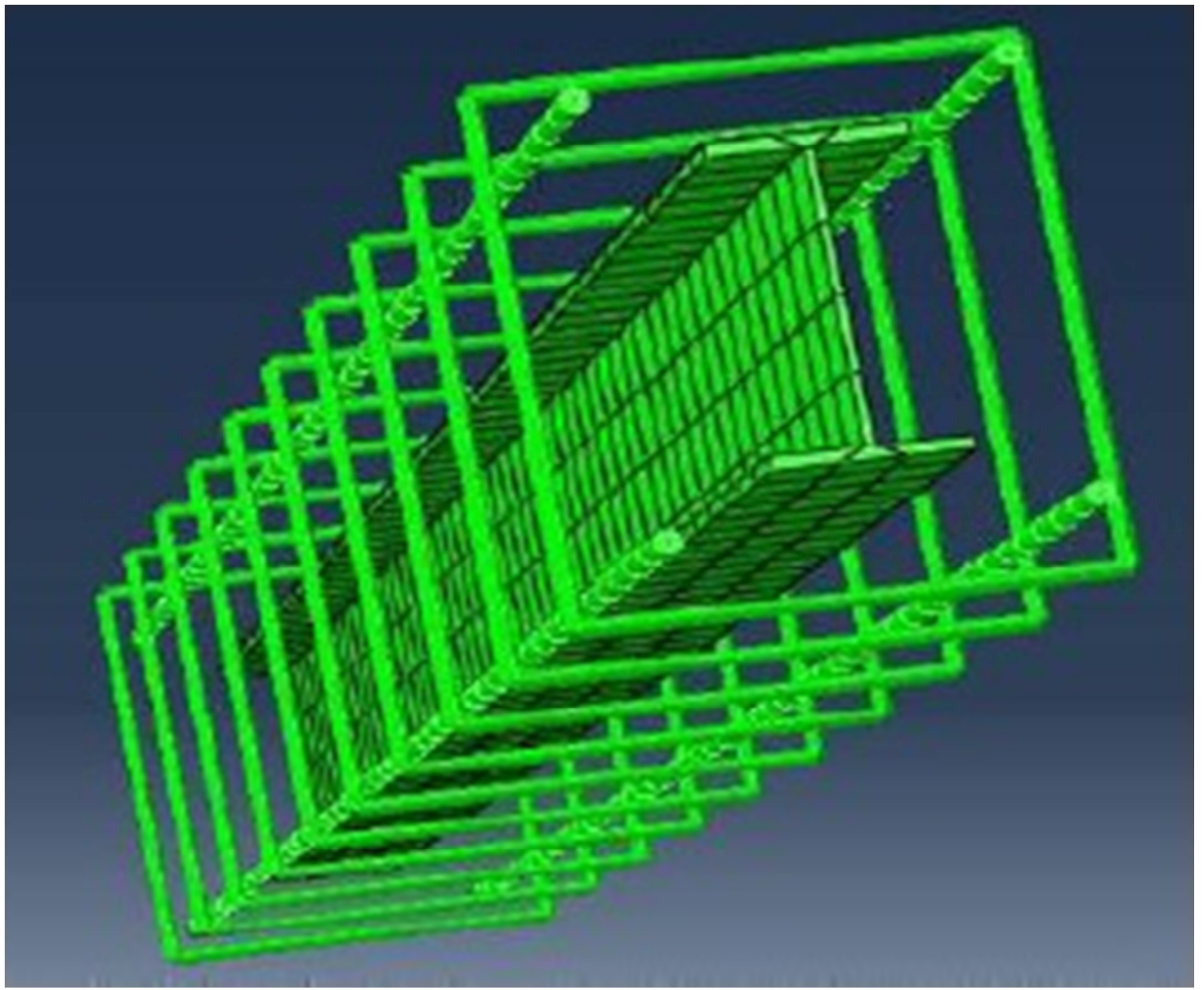

Fig. 8. Modelled columns view without showing concrete

In the steel - concrete composite column SRC, lengths equal to $2 \mathrm{~m}, 3 \mathrm{~m}, 4 \mathrm{~m}$, and axial load with eccentricity of $1 \mathrm{~mm}, 10 \mathrm{~mm}, 30 \mathrm{~mm}, 50 \mathrm{~mm}, 150 \mathrm{~mm}$, $200 \mathrm{~mm}$, and $300 \mathrm{~mm}$ has been applied as well as columns of $5 \mathrm{~m}$ to $10 \mathrm{~m}$ and axial load with eccentricity of $1 \mathrm{~mm}$. 


\section{RESULTS}

First of all, in order to understand the eccentricity effect on SRC composite columns load capacity, an axial deformation force diagram with abscissa of $2 \mathrm{~m}$ for different eccentricities has been plotted in figure 9. Then, to observe the length extension effect on SRC columns load capacity, axial deformation- axial force diagrams have been plotted with abscissa at $2 \mathrm{~m}$ and $5 \mathrm{~m}$ and eccentricity of $1 \mathrm{~mm}$, shown in figure 10 .

As can be observed, load capacity is reduced with eccentricity in concrete due to the bending (flexure) moment and axial force with bending moment interaction increase. Also, with length increase, load capacity and SRC columns stiffness has decreased. By increasing the ratio of efficient length to gyration radius of the minimum section of a pressure member, buckling inclination increases. Buckling is technically under member elastic instability. Inclination criteria with respect to buckling is the ratio of effective length to gyration radius of a minimum section. This is technically referred to as "slenderness coefficient" and is calculated by the equation $\lambda=\frac{\mathrm{KL}_{u}}{\mathrm{r}}$ where $\mathrm{k}$ is efficient length coefficient, $\mathrm{L}_{\mathrm{u}}$ is non- braced length of pressure member and $r=\sqrt{\frac{I}{A}}$ is gyration radius of minimum section. Where $\mathrm{I}$ is minimum inertia moment and $\mathrm{A}$ is member section area, $\mathrm{k}$ is dependent on the support conditions of the two end columns, taken as 2.2 in this study.

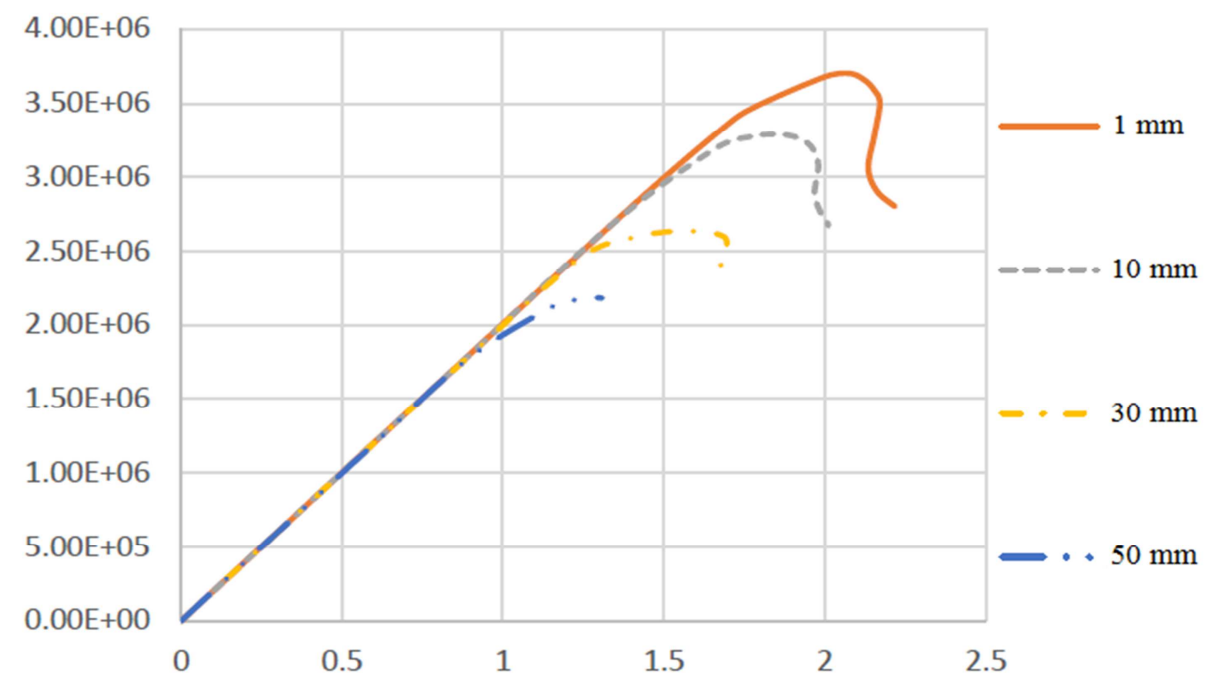

Fig. 9. Axial deformation- force diagram for $2 \mathrm{~m}$ columns with various eccentricities 


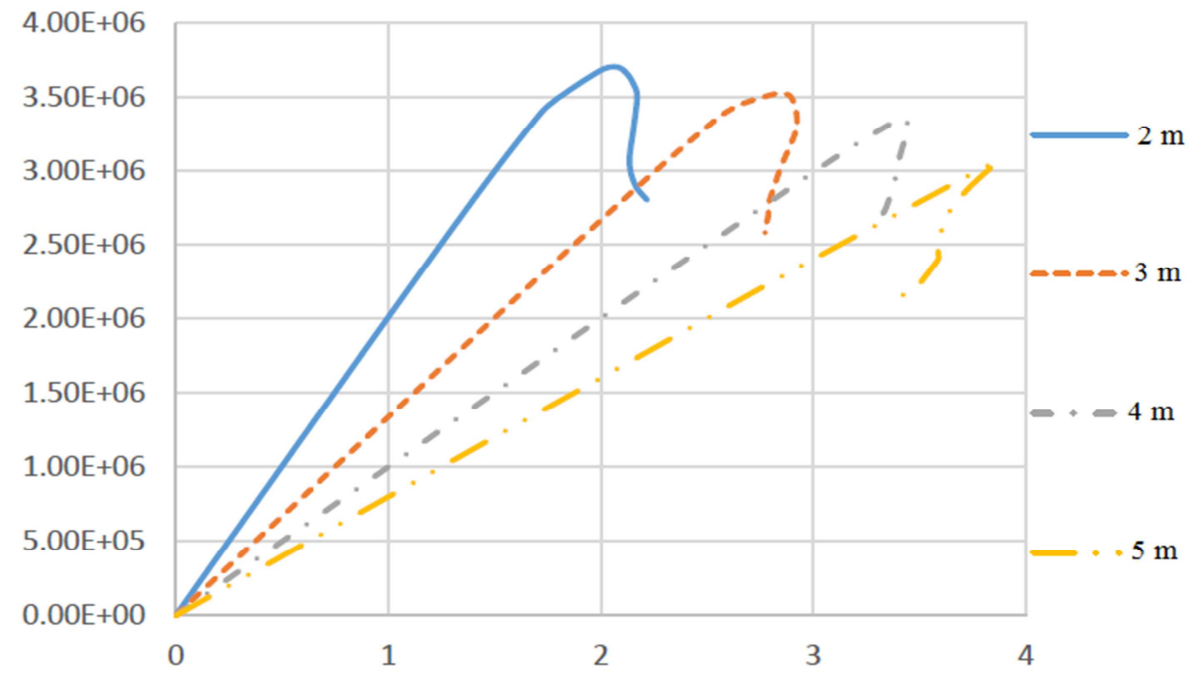

Fig. 10. Axial deformation- force diagram in different lengths with $1 \mathrm{~mm}$ eccentricity

Now, the column curve for slenderness coefficient - axial force is plotted for lengths of $2 \mathrm{~m}$ to $10 \mathrm{~m}$ in $1 \mathrm{~mm}$ eccentricity. This curve is shown in figure 11 .

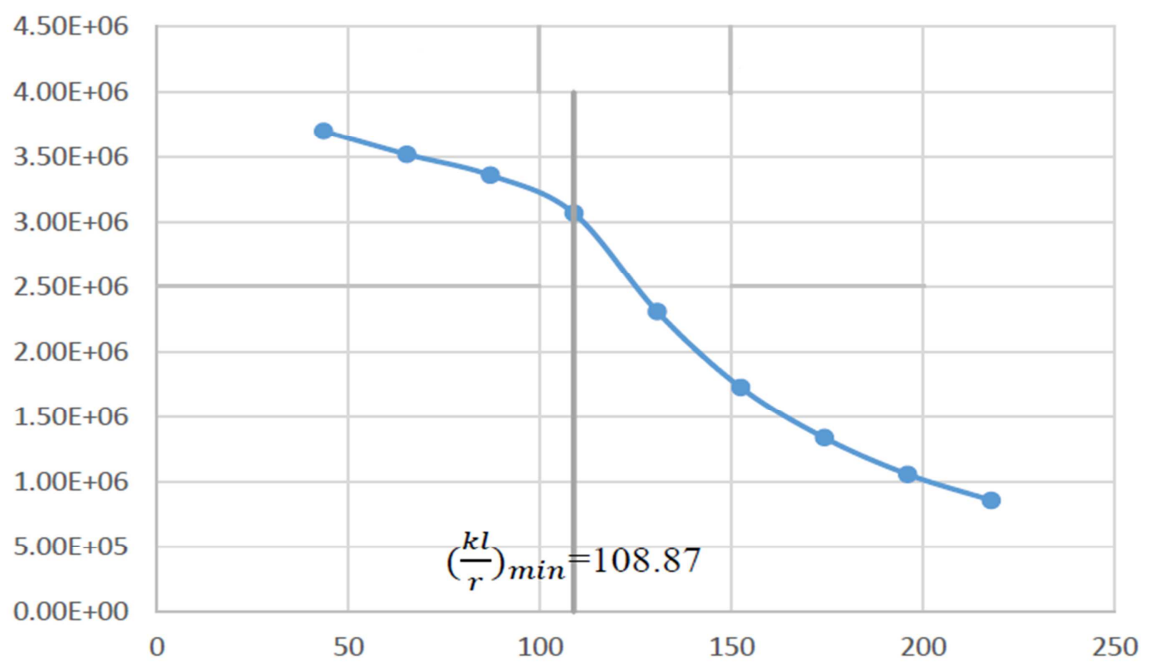

Fig. 11. Column curve (slenderness coefficient - axial force)

This curve shows the critical load reduction due to slenderness increase. In this curve, it is observed that for slender columns, buckling load is less than column breakage axial force. So, there is a minimum slenderness limit below which 
column destruction occurs simply due to the breakage effect of the materials without the buckling phenomenon. For amounts larger than $\left(\frac{\mathrm{KL}}{\mathrm{r}}\right)$, column destruction occurs by buckling. Buckling load also drastically decreases with slender increase. What we can see from this curve is that for columns shorter than $5 \mathrm{~m}$ material breakage, and for columns taller than $5 \mathrm{~m}$, buckling occurs. Using the find graph program, equation (5.1), $\lambda$ (slender coefficient) and $P_{n}$ (net axial capacity) is presented. Using this equation, we can calculate the slender coefficient and column net load capacity as follows:

$P_{n}=333 \times 10^{8} \times \frac{\lambda^{2}-192.7 \lambda+10189.62}{\left(\lambda^{2}-77.24 \lambda+10145.97\right)\left(\lambda^{2}-18.02 \lambda+10553.48\right)}$

Where $P_{n}$ is axial net capacity. In figure 12 , the amount gained by the presented equation has been compared with finite element method results. As we can see, results from equation (5.1) match well with the finite element method results.

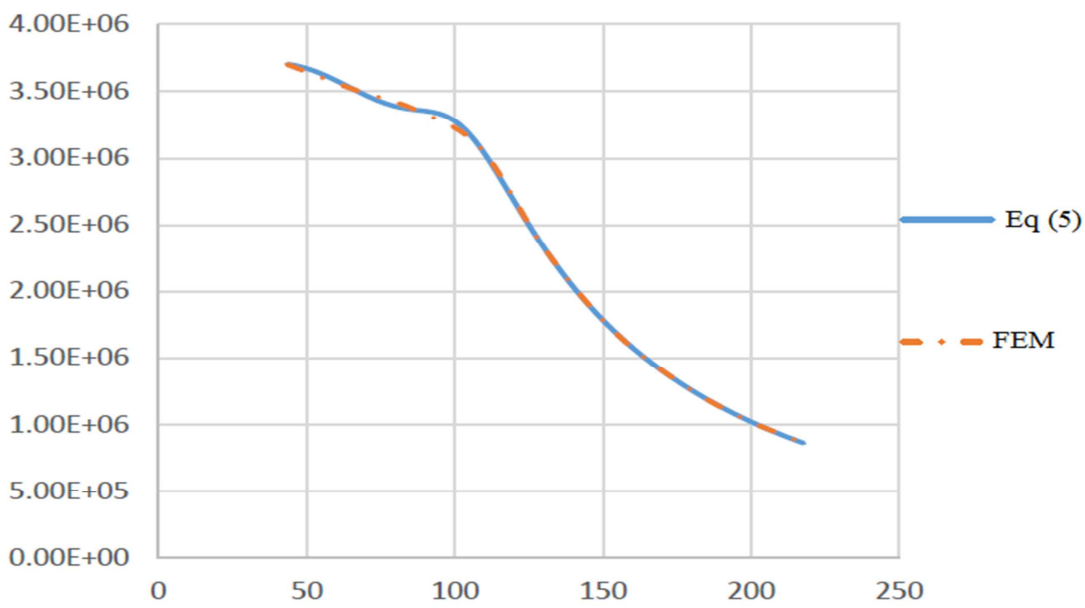

Fig. 12. Comparing finite element results and equation (5.1)

Now, in order to draw the axial force and bending moment interaction curves, we must multiply the calculated loads capacity by the applied eccentricities to get bending moments. In table 1, estimated amounts have been brought to three columns $2 \mathrm{~m}, 3 \mathrm{~m}$, and $4 \mathrm{~m}$. Figures for axial force and bending moment interaction have been plotted for three lengths; $2 \mathrm{~m}, 3 \mathrm{~m}$, and $4 \mathrm{~m}$ as shown in figure 13.

A) When all or the greater part of section 13 is under pressure stresses; in such a way that before flowing of steel tension, pressure deformation reaches 0.003 in the concrete, we call this area the "Pressure control area". 
B) The main part of the section is under tension resulting in pressure relative deformation in the concrete which reaches 0.003 , tension relative deformation in the rebars is larger than the relative deformation of the flow point (yielding). This area is called the "tension control area".

Table 1. Axial force and bending moment for three lengths $2 \mathrm{~m}, 3 \mathrm{~m}, 4 \mathrm{~m}$

\begin{tabular}{|c|c|c|c|c|c|c|c|c|c|}
\hline & eccentricity & 1 & 10 & 30 & 50 & 70 & 150 & 200 & 300 \\
\hline \multicolumn{10}{|c|}{ Lengtb(m) } \\
\hline \multirow[b]{2}{*}{2} & $P\left(10^{6} \mathrm{~N}\right)$ & 3.70 & 3.29 & 2.63 & 2.18 & 1.66 & 0.421 & 0.265 & 0.131 \\
\hline & $\mathrm{M}\left(10^{8} \mathrm{~N}-\mathrm{mm}\right)$ & 0.037 & 0.329 & 0.789 & 1.09 & 1.162 & 0.6315 & 0.53 & 0.393 \\
\hline \multirow[b]{2}{*}{3} & $\mathrm{P}\left(10^{6} \mathrm{~N}\right)$ & 3.52 & 3.06 & 2.39 & 1.95 & 1.61 & 0.419 & 0.265 & 0.151 \\
\hline & $\mathrm{M}\left(10^{8} \mathrm{~N}-\mathrm{mm}\right)$ & 0.0352 & 0.306 & 0.717 & 0.96 & 1.127 & 0.6285 & 0.53 & 0.453 \\
\hline \multirow[b]{2}{*}{4} & $P\left(10^{6} \mathrm{~N}\right)$ & 3.36 & 2.76 & 2.11 & 1.69 & 1.32 & 0.403 & 0.167 & 0.097 \\
\hline & $\mathrm{M}\left(10^{8} \mathrm{~N}-\mathrm{mm}\right)$ & 0.036 & 0.276 & 0.633 & 0.845 & 0.924 & 0.6045 & 0.334 & 0.291 \\
\hline
\end{tabular}

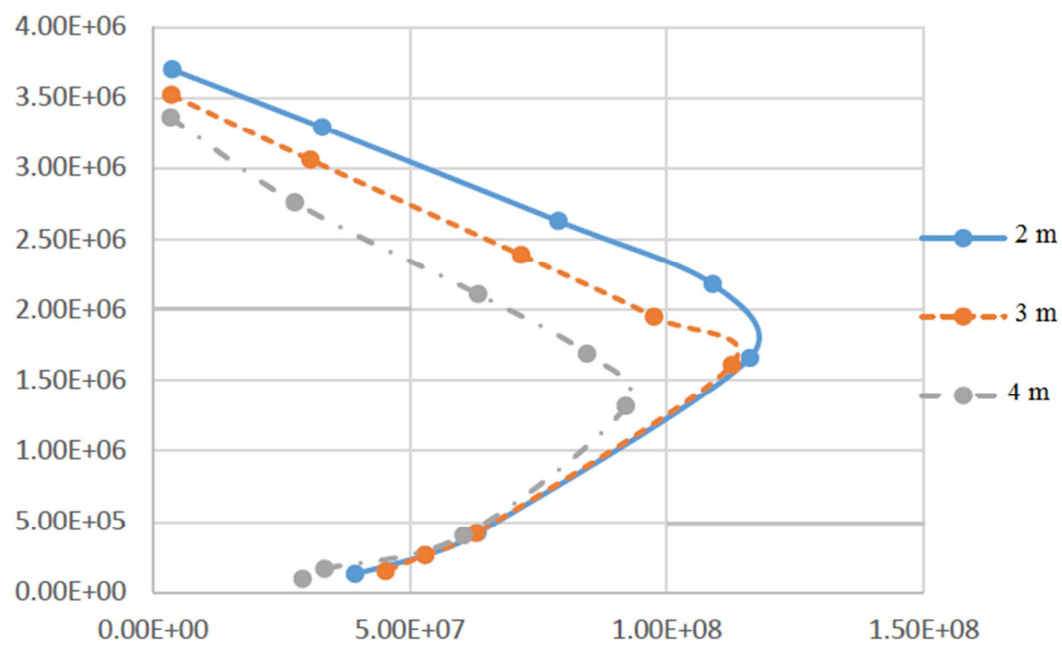

Fig. 13. Interaction axial force and bending moment for three lengths $2 \mathrm{~m}, 3 \mathrm{~m}, 4 \mathrm{~m}$

According to the diagrams of interaction of axial force and bending moment and also table 1, and according to unchanged cross-sectional area, Balance point in all three lengths is $e_{b}=70 \mathrm{~mm}$. Using Find Graph software, three equation diagrams of dimension - free interaction axial force and bending moment for 
lengths $2 \mathrm{~m}, 3 \mathrm{~m}$, and $4 \mathrm{~m}$ have been presented by equations (5.2), (5.3), and (5.4), respectively.

$$
\begin{array}{ll}
\mathrm{m}=\frac{0.06234+0.94241 \mathrm{n}-0.98209 \mathrm{n}^{2}}{20.26671+0.26282 \mathrm{n}-0.93895 \mathrm{n}^{2}+\mathrm{n}^{3}} & \mathrm{~L}=2 \mathrm{~m} \\
\mathrm{~m}=\frac{99696.9+511550 \mathrm{n}-590708 \mathrm{n}^{2}}{329305-608029 \mathrm{n}+773167 \mathrm{n}^{2}+\mathrm{n}^{3}} & \mathrm{~L}=3 \mathrm{~m} \\
\mathrm{~m}=\frac{0.02774+1.00045 \mathrm{n}-0.99753 \mathrm{n}^{2}}{0.17893+0.29032 \mathrm{n}-0.57678 \mathrm{n}^{2}+\mathrm{n}^{3}} & \mathrm{~L}=4 \mathrm{~m}
\end{array}
$$

In order to find another equation, plus the equation (5.1) to design a reinforced SRC column with IPE, dimensionless diagrams $n=\frac{P}{P_{\max }}$ (ratio of axial force to net axial capacity) are plotted versus $\frac{e}{D}$ (ratio of eccentricity to section dimension along the bending). These diagrams are plotted in figure 15. As we can see, by increasing length, the eccentricity increase effect encourages reduction of column load capacity. The diagrams decrease with more gradient due to the slender increase. According to these diagrams, equation (5.5), (5.6) and (5.7). Between these two, parameters are presented for lengths $2 \mathrm{~m}, 3 \mathrm{~m}$, and $4 \mathrm{~m}$ respectively by find graph. According to them, $\mathrm{n}$ is calculated based on $\frac{e}{D}$.where $e$ is axial load eccentricity, D is column dimension along the bending, and $\mathrm{n}$ is the ratio of axial load to maximum axial load.

$$
\begin{array}{ll}
\operatorname{Ln}(\mathrm{n})=0.00587-3.9526 \frac{\mathrm{e}}{\mathrm{D}} & L=2 m \\
\operatorname{Ln}(\mathrm{n})=-0.01844-3.9326 \frac{\mathrm{e}}{\mathrm{D}} & L=3 m \\
\operatorname{Ln}(\mathrm{n})=-0.03406-4.6052 \frac{\mathrm{e}}{\mathrm{D}} & L=4 m
\end{array}
$$




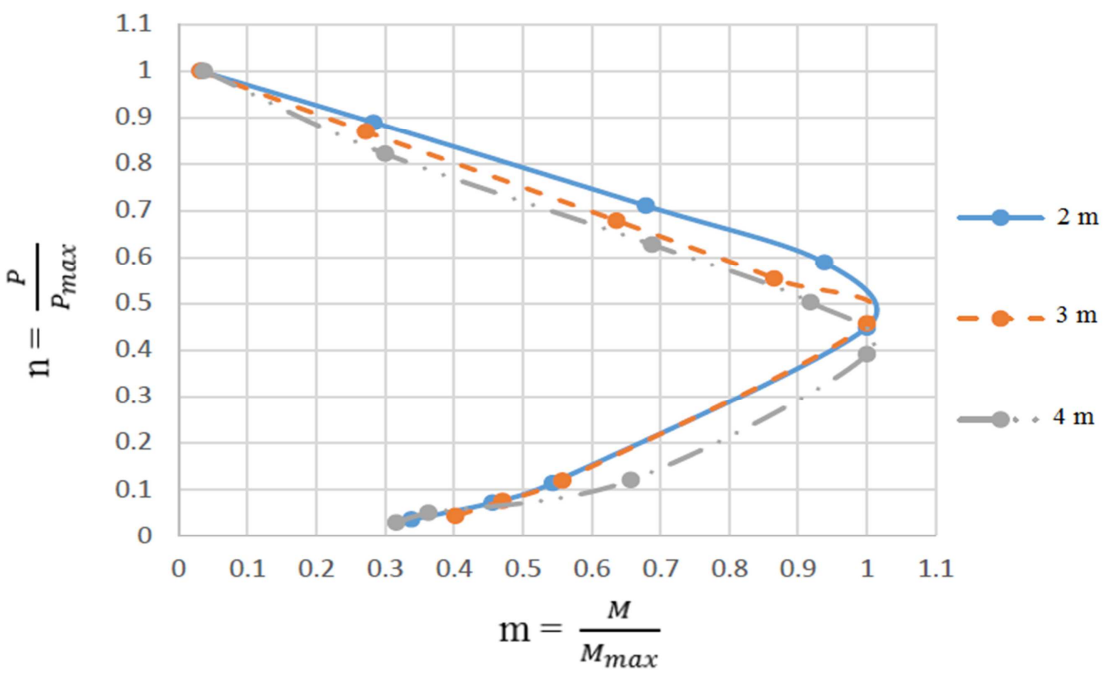

Fig. 14. Diagram of dimension - free interaction axial force and bending moment

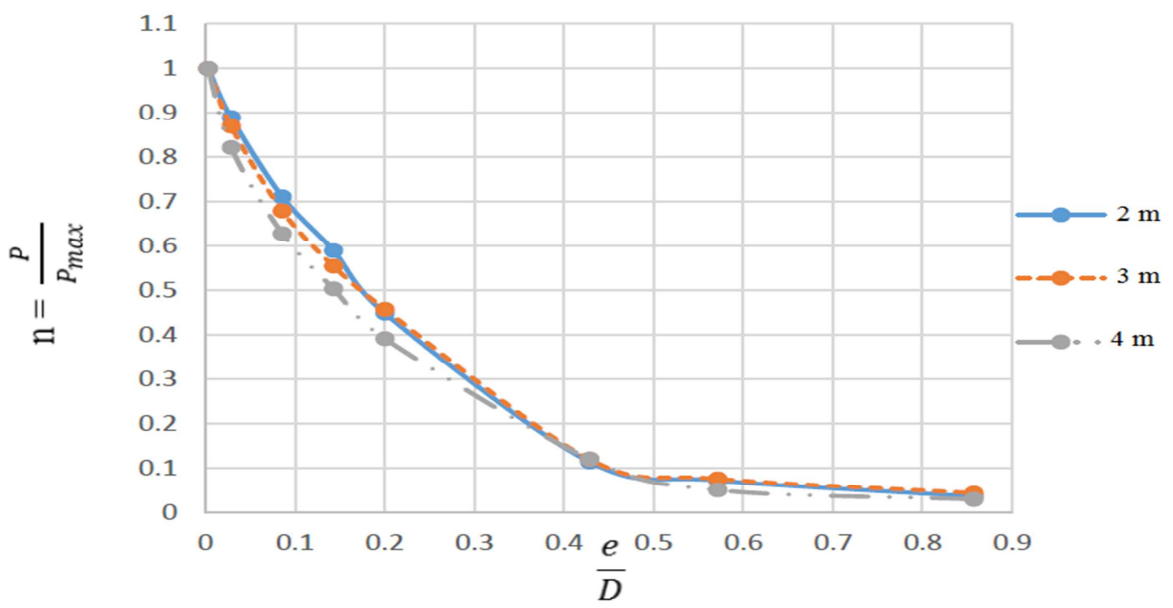

Fig. 15. Diagram of eccentricity effect in reducing column load capacity

We can design the column by calculating $m$ and $n$ according to maximum axial force amounts and bending moment (Table 1). Also, to calculate the bending moment, we can multiply the "e amount" by the axial force amount gained from equations (5.5) to (5.7).

According to the $10^{\text {th }}$ topic of the national institute (clause 1-2-8-7-10), axial elements design pressure resistance with complex section in concrete is $\varphi_{c} P_{n}$, where $\varphi_{c}$ resistance reduction coefficient is 0.15 and $P_{n}$ is nominal pressure 
resistance which must be determined based on the bending buckling limit mode according to column slenderness by equations (5.8) to (5.10).

$$
\begin{aligned}
& \text { A) for } \frac{\mathrm{P}_{\mathrm{no}}}{\mathrm{P}_{\mathrm{e}}} \leq 2.25 \\
& \mathrm{P}_{\mathrm{n}}=\mathrm{P}_{\mathrm{no}}\left[0.658^{\mathrm{Pno} / \mathrm{Pe}}\right] \\
& \text { B) for } \frac{\mathrm{P}_{\mathrm{no}}}{\mathrm{P}_{\mathrm{e}}}>2.25 \\
& \mathrm{P}_{\mathrm{n}}=0.877 \pi^{2} \frac{\mathrm{E}_{\mathrm{s}} \mathrm{I}_{\mathrm{s}}+0.5 \mathrm{E}_{\mathrm{s}} \mathrm{I}_{\mathrm{sr}}+\mathrm{C}_{1} \mathrm{E}_{\mathrm{c}} \mathrm{I}_{\mathrm{c}}}{(\mathrm{KL})^{2}} \\
& \mathrm{P}_{\mathrm{no}}=\mathrm{F}_{\mathrm{y}} \mathrm{A}_{\mathrm{s}}+\mathrm{F}_{\mathrm{ysr}} \mathrm{A}_{\mathrm{sr}}+0.85 \mathrm{~F}_{\mathrm{c}} \mathrm{A}_{\mathrm{c}}
\end{aligned}
$$

Where in (5.9) $C_{l}$ is the coefficient for pressure element efficient rigidity determination with complex section in concrete which is calculated by equation (5.11).

$C_{1}=0.1+2 \frac{A_{s}}{A_{s}+A_{c}} \leq 0.3$

$\mathrm{P}_{\mathrm{no}}$ in the $10^{\text {th }}$ topic of the national institute of building is matched but there is no match between these results and the presented $P_{n}$ in this regulation. This is because the modelled SRS column with $5 \mathrm{~m}$ length in equations (5.8) to (5.11) uses index ' $s$ ' for steel, 'c' for concrete, and 'sr' for rebar. "I" is inertia moment to neutral string, " $\mathrm{E}$ " is modulus elasticity, " $\mathrm{F}$ " is yielding stress, " $\mathrm{A}$ " is section Area, " $\mathrm{K}$ " is effective length factor, and " $\mathrm{L}$ " is axial element non- bracing length. Equations in the $10^{\text {th }}$ topic of the national institute are the same as the equations in AISC [3].

Since the columns are modelled as one side free, one side hold type, then $\mathrm{K}=2$ [10] and is calculated for the three lengths $2 \mathrm{~m}, 3 \mathrm{~m}$, and $4 \mathrm{~m} \mathrm{P}_{\mathrm{n}}$. In table 2, the results of finite elements modelling, presented equations, and building national institute $10^{\text {th }}$ topic have been compared. Equation (5.1) has very good finite elements results compared to equations (5.5) to (5.7). Equation (5.5) is the ratio of finite elements result ability and equations (5.6) and (5.7) are the opposite of reliability. It is noteworthy that the result for $1 \mathrm{~mm}$ eccentricity is equal to "zero". Among the results gained by the finite elements, buckling equation and material cracking has occurred in smaller lengths. In $P_{n o}$ there is no sign of buckling and this equation is related to material yielding and breakage and in equation $\mathrm{P}_{\mathrm{n}}$, the buckling effect is observed. 
Table. 2. Comparing the presented equation results for SRC steel - concrete composite column load capacity

\begin{tabular}{|c|c|c|c|c|c|c|}
\hline & FEM & & & \multirow{2}{*}{\multicolumn{3}{|c|}{$10^{\text {th }}$ topic of national institute of building }} \\
\hline & & \multirow{2}{*}{$\begin{array}{r}\text { Eq. (5.1) } \\
\mathrm{P}\left(10^{6} \mathrm{~N}\right)\end{array}$} & \multirow{2}{*}{$\begin{array}{l}\text { Eq. (5.5) to (5.7) } \\
\mathrm{P}\left(10^{6} \mathrm{~N}\right)\end{array}$} & & & \\
\hline Length $(\mathrm{m})$ & $\mathrm{P}\left(10^{6} \mathrm{~N}\right)$ & & & $\mathrm{P}_{\mathrm{no}}\left(10^{6} \mathrm{~N}\right)$ & $\mathrm{P}_{\mathrm{e}}\left(10^{6} \mathrm{~N}\right)$ & $\mathrm{P}_{\mathrm{n}}\left(10^{6} \mathrm{~N}\right)$ \\
\hline 2 & 3.70 & 3.7044 & 3.7218 & \multirow{3}{*}{3.5486} & 3.4446 & 2.3057 \\
\hline 3 & 3.52 & 3.5240 & 3.4557 & & 1.5309 & 1.3426 \\
\hline 4 & 3.36 & 3.3634 & 3.2475 & & 86.1148 & 0.7552 \\
\hline
\end{tabular}

\section{CONCLUSION}

Eccentricity increase caused column load capacity decrease due to bending moment increase and interaction between axial force and bending moment.

Column length increase caused load capacity reduction and column stiffness reduction since, by increasing the ratio of efficient length to gyration radius, a minimum section of pressure element (member) inclination to buckling increases within it.

In the modelled SRC column, according to column curve, minimum slenderness limit is for $5 \mathrm{~m}$ length meaning that, for lengths smaller than $5 \mathrm{~m}$, material breakage occurred and for lengths larger than that, buckling occurred.

The relationship between slenderness coefficient and net axial capacity is presented and is a good match with the finite element results. For the modelled SRC column, balance eccentricity is $10 \mathrm{~mm}$.

With length increase, the eccentricity increase effect rises in column load capacity reduction.

For the lengths $2 \mathrm{~m}, 3 \mathrm{~m}$, and $4 \mathrm{~m}$ the relationship between the ratio of eccentricity to column section dimension and the ratio of axial force to net axial capacity are presented as well as three relationships between ratios of mentioned axial forces and the ratio of bending moment to maximum bending moment is also presented.

Among the results gained by finite element and equation $\mathrm{P}_{\mathrm{no}}$ in the building national institute $10^{\text {th }}$ topic there is a match; however, there is no match between these results and amounts of $\mathrm{P}_{\mathrm{n}}$ equations, the reason being that the $5 \mathrm{~m}$ length column buckled and smaller length columns suffered material breakage. In $\mathrm{P}_{\mathrm{no}}$, there is no trace of buckling and this equation is related to materials yielding and breakage, and in equation $\mathrm{P}_{\mathrm{n}}$, the buckling effect is observed. 


\section{REFERENCES}

1. Abdelbaky, H. Nonlinear micromechanics-based finite element analysis of the interfacial behavior of FRP-strengthened reinforced concrete beams. Department of civil engineering, Sherbrook University.

2. Ahmadi, C, Kheyroddin, A and Naderpour, H 2010. Investigation the behavior and comparison of reliable codes on concrete-steel composite columns. Journal of Modeling in Engineering, 8(22), 37-49.

3. AISC 360-05 2005. Specification for structural steel buildings. Chicago, Illinois, USA: America Institute for Steel Construction, ANSI/AISC 360-05, Reston,

4. Bzdawka, K. Composite Column-Calculation Examples, Tampere University of Technology. Department of Civil Engineering, Structural Engineering Research Report 147.

5. Chen, CC and Lin, NJ 2006. Analytical Model for Predicting Axial Capacity and Behavior of Concrete Encased Steel Composite Stub Columns. Journal of Constructional Steel Research, 62, 424-433.

6. EL-Tawil, S and Deierlein GG 1999. Strength and Ductility of Concrete Encased Composite Columns. Journal of Structural Engineering, 125(9), 1009-1019.

7. Fakhri, SR 1995. Investigating steel columns filled with concrete and related Joints, master project in construction. technical college of Tehran university.

8. Liu, GQ and Owen, DRJ 1986. Ultimate load behaviour of reinforced concrete plates and shells under dynamic transient loading. International Journal for Numerical Methods in Engineering, 22(1), 189-208.

9. Mostafinejad, D 2011. Concrete Structures. Arkan publication, 39-53.

10.Popov. Egor Paul 1952. Introduction to Mechanics of Materials. New York: Prentice-Hall.

11.Soroushnia, S, Najafi, H, Momghani, M, Mehrvand, M and Mehrvand, MH 2013. Most accomplished Reference in practical ABAQUS (advanced level. Civil engineering). Negarandeh publication.

12.Todeschini, CE, Bianchini, AC and Kesler, CE 1964. Behavior of Concrete Columns Reinforced with High Strength Steel. Committee of Concrete Reinforcing Bar Producers, America Iron and Steel Institute.

The editor received the manuscript on 24.05.2019 